\title{
The mode of action of dinitrophenols on the different phosphorylating steps
}

Citation for published version (APA):

Hemker, H. C. (1964). The mode of action of dinitrophenols on the different phosphorylating steps. Biochimica et Biophysica Acta (BBA) - Specialized Section on Enzymological Subjects, 81(1), 9-20. https://doi.org/10.1016/0926-6569(64)90330-X

Document status and date:

Published: 01/01/1964

DOI:

10.1016/0926-6569(64)90330-X

Document Version:

Other version

\section{Please check the document version of this publication:}

- A submitted manuscript is the version of the article upon submission and before peer-review. There can be important differences between the submitted version and the official published version of record.

People interested in the research are advised to contact the author for the final version of the publication, or visit the DOI to the publisher's website.

- The final author version and the galley proof are versions of the publication after peer review.

- The final published version features the final layout of the paper including the volume, issue and page numbers.

Link to publication

\footnotetext{
General rights rights.

- You may freely distribute the URL identifying the publication in the public portal. please follow below link for the End User Agreement:

www.umlib.nl/taverne-license

Take down policy

If you believe that this document breaches copyright please contact us at:

repository@maastrichtuniversity.nl

providing details and we will investigate your claim.
}

Copyright and moral rights for the publications made accessible in the public portal are retained by the authors and/or other copyright owners and it is a condition of accessing publications that users recognise and abide by the legal requirements associated with these

- Users may download and print one copy of any publication from the public portal for the purpose of private study or research.

- You may not further distribute the material or use it for any profit-making activity or commercial gain

If the publication is distributed under the terms of Article $25 \mathrm{fa}$ of the Dutch Copyright Act, indicated by the "Taverne" license above, 


\title{
THE MODE OF ACTION OF DINITROPHENOLS ON THE DIFFERENT PHOSPHORYLATING STEPS *
}

\author{
H. C. HEMKER \\ Laboratory of Physiological Chemistry, University of Amsterdam, \\ Amsterdam (The Netherlands)
}

(Received May I7th, I963)

\section{SUMMARY}

I. Determinations of the concentration $\left(c_{\mathrm{aq}}\right)_{\text {opt }}$ of a dinitrophenol that induced maximal respiration in a medium deficient in phosphate and phosphate acceptor was carried out with different alkylnitrophenols and substrates (succinate, pyruvate $(+$ malate $)$, glutamate, $\beta$-hydroxybutyrate $)$ at various $\mathrm{pH}$ 's.

2. The $\mathrm{pH}$ optimum of maximally uncoupled succinate oxidation was $7 \cdot 4$, of maximally uncoupled pyruvate oxidation 6.8 .

3. The $\mathrm{p}\left(c_{1}\right)_{\mathrm{opt}}$, where $c_{1}$ is the calculated concentration of uncoupling phenol in the lipid phase, is a linear function of $\mathrm{pH}$, the slope of the line relating these quantities being o with succinate and -0.5 for NAD-linked substrates; an exceptional case is formed when the respiration of pyruvate (+ malate) is uncoupled by alkyldinitrophenols, in which case the slope is 0.

4. From a consideration of the reaction kinetics it appears that for systems in which $\mathrm{dp}\left(c_{1}\right)_{\mathrm{opt}} / \mathrm{dpH}$ is zero, uncoupling and inhibition by phenols $(\Phi)$ is best explained by the reactions:

$$
\mathrm{A} \sim \mathrm{I}+\Phi \rightarrow \mathrm{A}+\mathrm{I}-\Phi \quad \mathrm{I}-\Phi \rightleftharpoons \mathrm{I}+\Phi
$$

where $\mathrm{A}$ is an oxidized member of the respiratory chain, and $\mathrm{A} \sim \mathrm{I}$ an intermediate of oxidative phosphorylation. When the slope is -0.5 the sequence

$$
\mathrm{A} \sim \mathrm{I}+\Phi \rightarrow \mathrm{A}+\mathrm{I}-\Phi \quad \mathrm{I}-\Phi+\mathrm{H}^{+} \rightleftharpoons \mathrm{I}+\Phi
$$

appears to be the most likely.

5. On basis of the difference in the relation between $\mathrm{p}\left(c_{\mathrm{aq}}\right)_{\text {opt }}$ and $\mathrm{pH}$ for different NAD-linked substrates it is concluded that mitochondrial NAD + associated with the different substrates is present in different compartments, and that the whole phosphorylation system connected with a particular substrate must be localized in the same mitochondrial compartment. The compartments differ in their lipophilic character.

* This work was part of the M.D. thesis of the author which was published in Dutch in April I962 (ref. I). 


\section{INTRODUCTION}

In the preceding paper ${ }^{2}$ it was concluded (I) that dinitrophenols have a specific inhibitory action on the uncoupled respiration and the ATPase of intact rat-liver mitochondria; (2) that dinitrophenols uncouple by reaction with a high-energy intermediate normally involved in the transfer of the energy derived from electron transport to ATP synthesis. At present there are no reasons to assume that the highenergy intermediate involved does not contain a member of the respiratory chain (A) and it will be denoted as $\mathrm{A} \sim \mathrm{I}$, although it may well be that the coupling process is much more complicated than suggested by the minimum scheme shown in the preceding paper.

The experiments leading to the recognition of the role of lipid solubility of uncoupling agents ${ }^{3,4}$ and those described in the preceding papers ${ }^{2,5}$ revealed a variation of $\left(c_{1}\right)_{\text {opt }}{ }^{4}$ with $\mathrm{pH}$ which remained to be investigated further. In the present paper, this variation is analysed in more detail in an attempt to clarify the mechanism of uncoupling. The results will be discussed in terms of the general theory of uncoupling proposed in the preceding paper ${ }^{2}$.

\section{METHODS}

The methods were essentially the same as described in the preceding paper ${ }^{2}$. The incubation mixtures are indicated in the legends to the figures.

\section{RESULTS}

\section{Determination of $\left(c_{a q}\right)_{\text {opt }}$ at different $p H$ 's for the oxidation of succinate}

In these experiments increasing concentrations of nitrophenol were added to the reaction mixture in the special vessel adapted to the oxygen polarograph described previously ${ }^{6}$. After each addition, the rate of $\mathrm{O}_{2}$ uptake was measured for a short period, after which a further amount of nitrophenol was added and the measurement of the $\mathrm{O}_{2}$ uptake repeated. Thus, a range of dinitrophenol concentrations was used in a single experiment. The concentration of nitrophenol inducing the highest rate of $\mathrm{O}_{2}$ consumption in an experiment at a given $\mathrm{pH}$ is indicated by a point in Fig. I. The neighbouring concentrations tested that induced a lower rate of $\mathrm{O}_{2}$ uptake are indicated by the ends of the horizontal line drawn through the point. The true $\left(c_{\mathrm{aq}}\right)_{\text {opt }}$ must, then, lie between the extremes indicated by the horizontal line.

It has been shown previously ${ }^{3,4}$ that Eqn. I

$$
\mathrm{p} c_{1}=\mathrm{p} c_{\mathrm{aq}}+\mathrm{pH}+\mathrm{p} Q+\log \left(K+\left[\mathrm{H}^{+}\right]+f Q\left[\mathrm{H}^{+}\right]\right)
$$

describes the relationship between the concentration $\left(c_{1}\right)$ of an uncoupling phenol in a lipid phase within the mitochondrion and the concentration $\left(c_{\mathrm{aq}}\right)$ in the surrounding aqueous medium, where $Q$ is the partition coefficient of the undissociated phenol molecule between lipid and water, $K$ is its acid dissociation constant, and $f$ is the ratio of the volumes of lipid and aqueous phases.

For dinitrophenols, the limiting case given by Eqn. 2 applies

$$
\mathrm{p} c_{1}=\mathrm{p} c_{\mathrm{aq}}+\mathrm{p} Q+\mathrm{pH}-\mathrm{p} K
$$




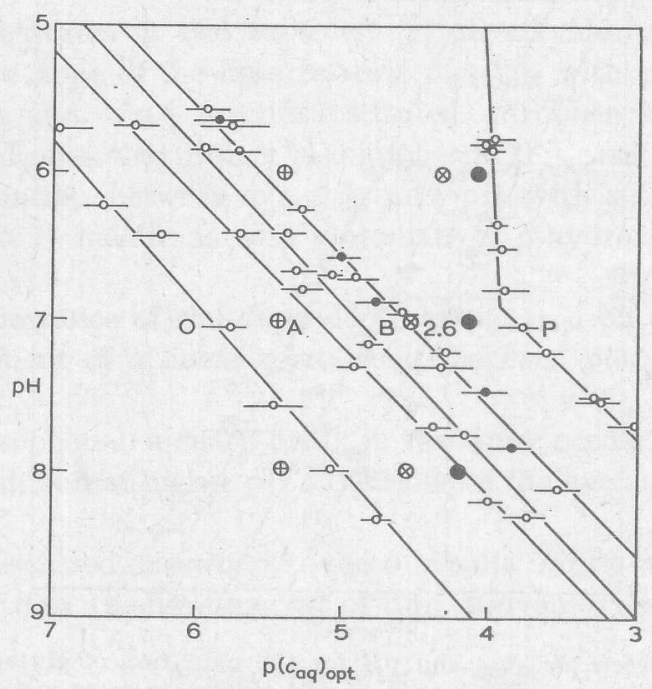

Fig. I. The relation between $\mathrm{p}\left(c_{\mathrm{aq}}\right)_{\mathrm{opt}}$ and $\mathrm{pH}$ for the oxidation of succinate. Reaction medium: I $5 \mathrm{mM} \mathrm{KCl}, 2 \mathrm{mM}$ EDTA, $50 \mathrm{mM}$ Tris- $\mathrm{HCl}, 5 \mathrm{mM} \mathrm{MgCl}_{2}$, $50 \mathrm{mM}$ sucrose, $60 \mathrm{mM}$ succinate, $3 \mathrm{mM}$ ATP (when present), I.2 mM Amytal. - - indicate the experiments where ATP was added, - $\mathrm{O}-$, where it was not added. The diagonals connect the values obtained with the same nitrophenol. O, 4-isooctyl-2,6-dinitrophenol; A, 4-isoamyl-2,6-dinitrophenol; B, 4-isobutyl-2,6dinitrophenol; $\mathrm{P}$, p-nitrophenol; $2.6,2,6$-dinitrophenol. When $\left(c_{1}\right)_{\text {opt }}$ is calculated from $\left(c_{\mathrm{aq}}\right)$ opt with use of the partition coefficient for a xylene-water system the points are obtained for alkyldinitrophenols, $\otimes$ for $p$-nitrophenol and $\oplus$ for 2,6-dinitrophenol.

This equation succesfully described the variation with $\mathrm{pH}$ of the ATPase induced by various phenols. The facts illustrated in Fig. I, viz. (I) that the effect of an uncoupling phenol on succinate oxidation depends upon the lipid solubility of the phenol, and (2) that the slope of the $\mathrm{pH}$-concentration curve for $\ddot{p}$-nitrophenol changes abruptly at a $\mathrm{pH}$ equal to the $\mathrm{p} K$ of $p$-nitrophenol, support the application of the equation to the effects on succinate oxidation. When the values for $\mathrm{p} Q$ obtained in a xylene-water ${ }^{4}$ system are applied to the data in Fig. I, the values of $\mathrm{p}\left(c_{1}\right)_{\text {opt }}$ are about the same for all the alkyldinitrophenols tested.

Although not too much significance is given to the actual value of $\left(c_{1}\right)_{\text {opt }}$ calculated from these data, since there is no reason to expect that the values of $Q$ obtained for the xylene-water system apply to the mitochondria, the agreement between the values for $\left(c_{1}\right)_{\text {opt }}$ for different alkyldinitrophenols supports the application of Eqn. 2 and indicates further that there is no fundamental difference in the mechanism of action of the different alkyldinitrophenols.

Fig. I shows that the relationship between $\mathrm{pH}$ and $\mathrm{p}\left(c_{\mathrm{aq}}\right)_{\text {opt }}$ for any one dinitrophenol may be described by Eqn. 3

$$
\mathrm{p}\left(c_{\mathrm{aq}}\right)_{\mathrm{opt}}=-\mathrm{pH}+b
$$

where $b$ is a constant. Combining Eqns. 2 and 3 yields Eqn. 4

$$
\mathrm{p}\left(c_{1}\right)_{\mathrm{opt}}=b+\mathrm{p} Q-\mathrm{p} K
$$

i.e. $\mathrm{p}\left(c_{1}\right)_{\mathrm{opt}}$ is independent of $\mathrm{pH}$. 


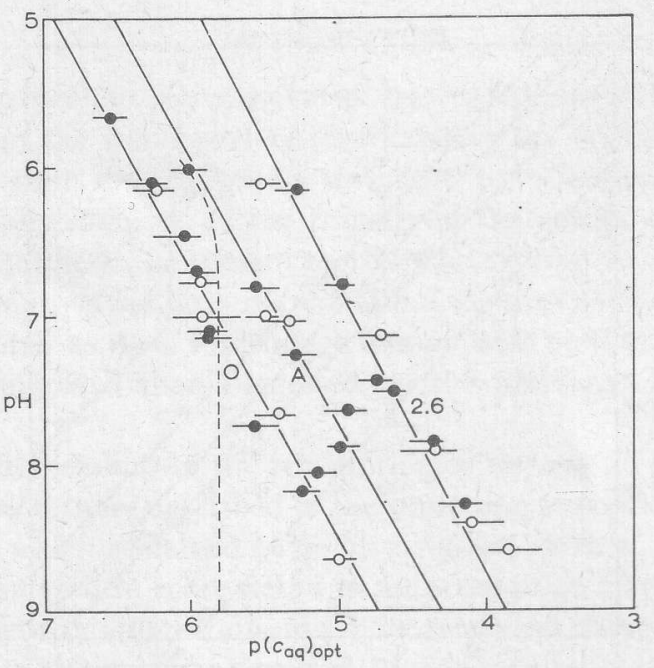

Fig. 2. The relation between $\mathrm{p}\left(c_{\mathrm{aq}}\right)_{\text {opt }}$ and $\mathrm{pH}$ for the oxidation of glutamate and $\beta$-hydroxybutyrate. Reaction medium as in Fig. I with $20 \mathrm{mM}$ glutamate or $20 \mathrm{mM} \beta$-hydroxybutyrate in place of succinate and no Amytal added. The letters denote the phenol used as in Fig. 1. - - $\beta$-hydroxybutyrate; - - glutamate; - . - , the left-hand line from Fig. 3 shown for comparison.

\section{Determination of $\left(c_{\mathrm{aq}}\right)_{\text {opt }}$ at different $p H$ 's for the oxidation of $N A D$-linked 6 ubstrates}

With glutamate or $\beta$-hydroxybutyrate as substrate (Fig. 2), the relationship between $\mathrm{p}\left(c_{\mathrm{aq}}\right)_{\text {opt }}$ and $\mathrm{pH}$ is given by Eqn. 5

$$
\mathrm{p}\left(c_{\mathrm{aq}}\right)_{\mathrm{opt}}=-0.5 \mathrm{pH}+b
$$

The results with pyruvate + malate as substrate (Fig. 3 ) differ from those obtained

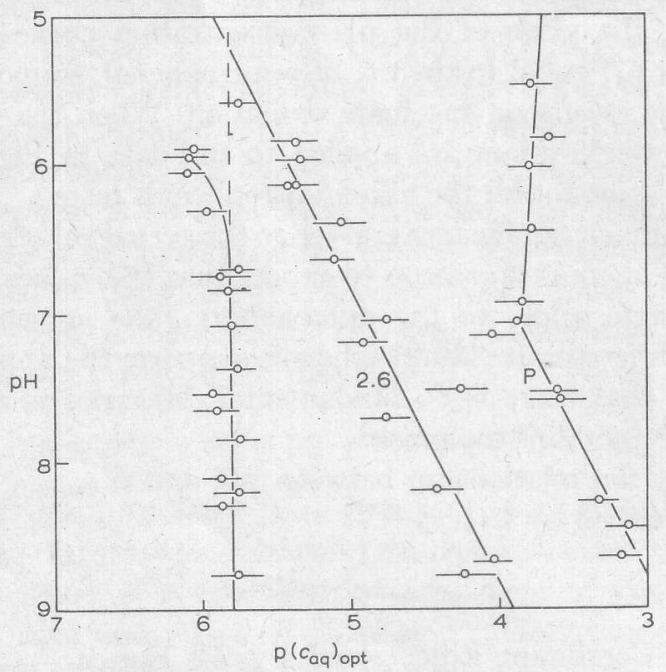

Fig. 3. The relation between $\mathrm{p}\left(c_{\mathrm{aq}}\right)_{\text {opt }}$ and $\mathrm{pH}$ for the oxidation of pyruvate ( + malate). Reaction medium as in Fig. 2, with $20 \mathrm{mM}$ pyruvate and $20 \mathrm{mM}$ malate as substrate. $\mathrm{P}$ and 2.6 denote the phenol used as in Fig. I. The left-hand (vertical) line connects the values obtained with all alkyl-substituted dinitrophenols. 
with the other substrates in two respects: (I) all alkyldinitrophenols fall on the same curve; (2) the slope of the lines relating $\mathrm{p}\left(c_{\mathrm{aq}}\right)_{\text {opt }}$ with $\mathrm{pH}$ is $\mathrm{o}$ in the case of alkyldinitrophenols and -0.5 for unsubstituted nitrophenols. However, the following evidence indicates that Eqn. I also applies in this case:

(I) The relationship between $\mathrm{p}\left(c_{\mathrm{aq}}\right)_{\text {opt }}$ and $\mathrm{pH}$ with 2,6 -dinitrophenol is the same with pyruvate + malate as with glutamate or $\beta$-hydroxybutyrate ( $c f$. Figs. 2 and 3$)$.

(2) The disappearance of the dependence of $\mathrm{p}\left(c_{\mathrm{aq}}\right)$ opt on $Q$ goes hand in hand with the establishment of a linear relationship between $\mathrm{p}\left(c_{\mathrm{aq}}\right)_{\text {opt }}$ and the amount of mitochondria 4 .

(3) With $p$-nitrophenol, a sharp break in the curve occurs at a $\mathrm{pH}$ equal to the $\mathrm{p} K$ of $p$-nitrophenol, and at higher $\mathrm{pH}$ 's the slope of the line again becomes equal to -0.5 .

As already discussed elsewhere ${ }^{4}$, these results imply that when pyruvate ( + malate) is substrate, the limiting case of Eqn. I given by Eqn. 6 aplies

$$
\mathrm{p}\left(c_{1}\right)_{\mathrm{opt}}=\mathrm{p}\left(c_{\mathrm{aq}}\right)_{\mathrm{opt}}+\log f
$$

i.e. $f Q\left[\mathrm{H}^{+}\right] \gg\left[\mathrm{H}^{+}\right]$and $\gg K$.

Thus, when pyruvate ( + malate) is substrate and an alkyldinitrophenol is the uncoupler, $f Q\left[\mathrm{H}^{+}\right] \gg\left[\mathrm{H}^{+}\right]$and $\gg K$. Under all other conditions, $f Q\left[\mathrm{H}^{+}\right] \ll\left[\mathrm{H}^{+}\right]$and $\ll K$.

\section{The pH-activity curve of the maximally stimulated respiring system}

Since the concentration of uncoupler that maximally stimulates succinate oxidation is strongly dependent upon the $\mathrm{pH}$, three different concentrations of uncoupler were tested at each $\mathrm{pH}$, all chosen to be close to the expected $\left(c_{\mathrm{aq}}\right)_{\text {opt }}$. The highest of the three values was taken to be the maximal activity at the pH tested. The optimal pH was about 7.4 (Fig. 4), the same as that found for the Amytal-

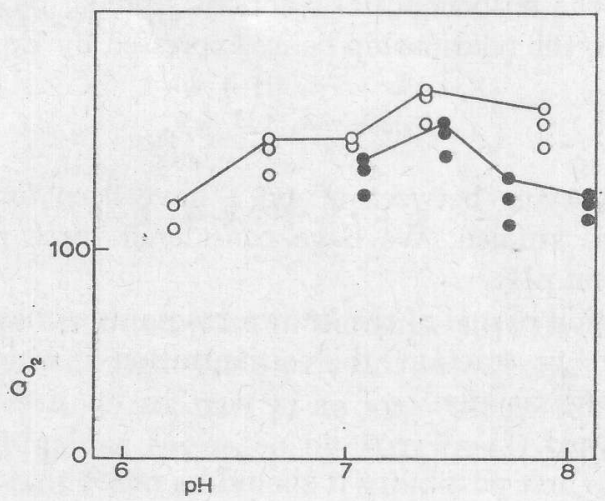

Fig. 4. The pH-activity curve of uncoupled succinate oxidation. The reaction velocities were measured manometrically. The reaction mixture was the same as in Fig. I. The black and white circles indicate two separate sets of experiments carried out with different mitochondrial preparations. No ATP added. At each pH 3 concentrations of 4-isobutyl-2,6-dinitrophenol chosen to be close to $\left(c_{\mathrm{aq}}\right)_{\text {opt }}$ were used. The highest value was taken to be the maximum activity at the given $\mathrm{pH}$, and the lines shown are drawn through these values. The other values are shown by the other points. 


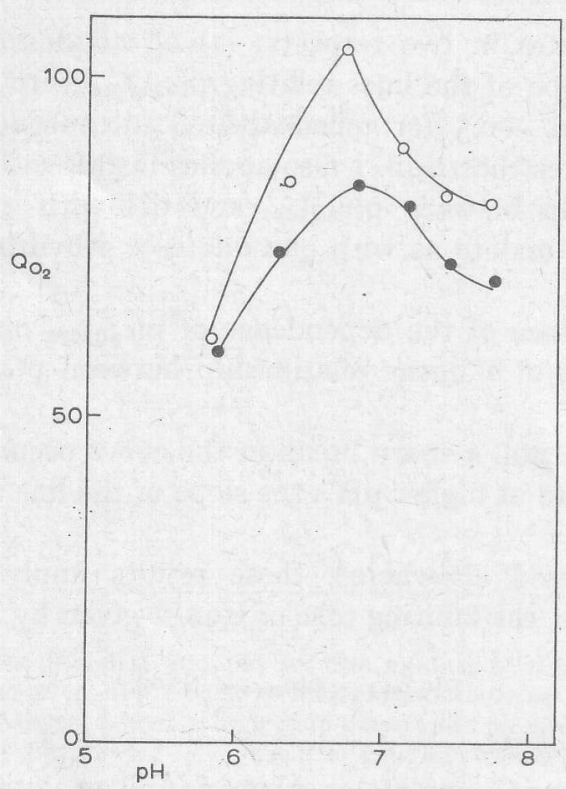

Fig. 5. The $\mathrm{pH}$ optimum of uncoupled pyruvate oxidation. Reaction medium as in Fig. 3. The reaction velocity was measured manometrically. - with $1.5 \mu \mathrm{M}$ 4-isooctyl-2,6-dinitrophenol; 0 - 0 , with $3 \mu \mathrm{M}_{4}$-isooctyl-2,6-dinitrophenol.

resistant ATPase ${ }^{5}$. Since $\left(c_{\mathrm{aq}}\right)_{\text {opt }}$ is independent of $\mathrm{pH}$ with pyruvate and alkyldinitrophenol, it was possible to determine the $\mathrm{pH}$-activity curve at a single concentration of uncoupler. The optimal $\mathrm{pH}$ was about 6.8 (Fig. 5).

\section{Theoretical considerations}

In the case of all the mitochondrial reactions studied, $\mathrm{p}\left(c_{1}\right)_{\text {opt }}$ was found to be a linear function of $\mathrm{pH}$, the relationship being expressed by Eqn. 7

$$
\mathrm{p}\left(c_{1}\right)_{\mathrm{opt}}=a_{1} \cdot \mathrm{pH}+b
$$

Various values of $a_{1}$.varying between 0 and $I$ have been found for the different mitochondrial reactions studied. We have considered three possible explanations for a dependence of $c_{1}$ on $\mathrm{pH}$ :

(I) The concentration of one of the known reactants varies with $\mathrm{pH}$.

(2) $\mathrm{H}^{+}$or an unknown reactant, the concentration of which is dependent upon the $\mathrm{pH}$, takes part in the reaction.

(3) $\mathrm{pQ}$ varies with $\mathrm{pH}$.

With regard to the first possibility it should be noted that the amounts of ATP or of substrate used were saturating ( $c f$. refs. 7,8$)$. Although the amount of an active enzyme can vary with $\mathrm{pH}$, such an effect would be revealed by a bend in the $\mathrm{p}\left(c_{\mathrm{aq}}\right)_{\mathrm{opt}}-\mathrm{pH}$ curve. This was not found. The third possibility was discarded as an explanation, since it seems very unlikely that the physical properties of the mitochondrion could be so altered - and reversibly - to account for a Ioo-fold variation 
of $Q$. For these reasons, we have preferred to interpret our results in terms of the second possibility. The concentration of the unknown reactant could be either linearly or inversely related to the concentration of $\mathrm{H}^{+} . \mathrm{H}^{+}$and $\mathrm{OH}^{-}$will be taken as representatives of these two cases.

If we assume that $\mathrm{H}^{+}$or $\mathrm{OH}^{-}$takes part in the reaction, we must also consider the possibility that the active species of the phenol is the phenolate ion, the concentration of which will be directly related to that of the undissociated phenol in the mitochondrial lipid (not to the concentration of phenolate ions in the medium).

The mechanism of uncoupling and inhibition by uncouplers proposed by HÜLSMANN ${ }^{9}$ will be used as our working hypothesis.

or

$$
\mathrm{AH}_{2}+\mathrm{B}+\underset{k_{\mathrm{g}}}{\stackrel{k_{1}}{\rightleftharpoons}} \mathrm{A} \sim \mathrm{I}+\mathrm{BH}_{2}
$$

$$
\begin{gathered}
\mathrm{ATP}+\mathrm{A}+\underset{k_{\mathrm{a}}}{\stackrel{\mathrm{I}_{1}}{\rightleftharpoons} \mathrm{A}} \sim \mathrm{I}+\mathrm{ADP}+\mathrm{P}_{\mathrm{I}} \\
\mathrm{A} \sim \mathrm{I}+\Phi \stackrel{\boldsymbol{\Phi}_{\mathrm{s}} \rightarrow \mathrm{A}}{\sim} \mathrm{I}-\Phi \\
\mathrm{I}-\underset{k_{6}}{\stackrel{k_{5}}{\rightleftharpoons} \mathrm{I}}+\Phi
\end{gathered}
$$

An alternative explanation of the inhibition, in which it is assumed that $k_{6}=0$, and the reverse of Reaction 3 is replaced by Reaction 4

will also be considered.

$$
\mathrm{I}-\boldsymbol{\Phi}+\underset{k_{8}}{\stackrel{k_{7}}{\rightleftharpoons}} \mathrm{I}-\Phi-\Phi
$$

The most likely point of action of $\mathrm{H}^{+}$or $\mathrm{OH}^{-}$is on the splitting of $\mathrm{I}-\Phi$ in Reaction 3, which may be written

or

$$
\mathrm{I}-\Phi+\mathrm{H}^{+} \underset{k_{6}}{\stackrel{k_{5}}{\rightleftharpoons}} \mathrm{I}+\Phi
$$

$$
\mathrm{I}-\Phi+\mathrm{OH}-\underset{k_{6}}{\stackrel{k_{5}}{\rightleftharpoons}} \mathrm{I}+\Phi
$$

Of course, these reactions are incomplete in the sense that the reaction partners on the left-hand side and on the right-hand side are not electrically equivalent. One possibility is that the reactions are part of an ionic-transport mechanism through the mitochondrial membrane as envisaged by MitchelL ${ }^{\mathbf{1 0}}$. Alternatively, I might be an acid or base ( $c f$. SLATER $\left.{ }^{11}\right)$.

Two assumptions have to be made before a kinetic treatment of Reactions $\mathrm{I}-5$ can be given.

(I) The velocity of Reaction 2 from right to left is negligibly small. This is a reasonable assumption, since it is proposed that the high-energy compound $\mathrm{A} \sim \mathrm{I}$ is converted into the low-energy $\mathrm{I}-\Phi$. 
(2) The concentrations of ATP and A are not rate-limiting. This is known to be the case with ATP? . That A is in excess is indicated by the finding of WADKINS AND LEHNINGER ${ }^{12}$ and CHEFURKA ${ }^{13}$ that only very rigorous reduction of the components of the respiratory chain leads to inhibition of the dinitrophenol-induced ATPase.

On the basis of these assumptions, we may write for the HÜLSMANN mechanism of the phenol-induced ATPase

$$
\begin{gathered}
\frac{\mathrm{d}[\mathrm{A} \sim \mathrm{I}]}{\mathrm{d} t}=k_{1}[\mathrm{I}]-k_{3}[\mathrm{~A} \sim \mathrm{I}][\Phi] \\
\frac{\mathrm{d}[\mathrm{I}-\Phi]}{\mathrm{d} t}=k_{3}[\mathrm{~A} \sim \mathrm{I}][\Phi]-k_{5}[\mathrm{I}-\Phi][w]+k_{6}[\mathrm{I}][\Phi]
\end{gathered}
$$

where w represents $\mathrm{H}^{+}$or $\mathrm{OH}^{-}$, according to whether Reaction 5 or $5^{\prime}$ is operating. In the steady state, $\mathrm{d}[\mathrm{A} \sim \mathrm{I}] / \mathrm{d} t=0, \mathrm{~d}[\mathrm{I}-\Phi] / \mathrm{d} t=0$, and $v=k_{3}[\mathrm{~A} \sim \mathrm{I}][\Phi]$. From this it follows that

$$
v=\frac{k_{1} k_{3} k_{5} \mathrm{i}[\Phi][w]}{k_{3} k_{6}[\Phi]^{2}+\left(k_{1} k_{3}+k_{3} k_{5}[w]\right)[\Phi]+k_{1} k_{5}[w]}
$$

where $\mathrm{i}=[\mathrm{I}]+[\mathrm{A} \sim \mathrm{I}]+[\mathrm{I}-\Phi]$.

$v$ will be a maximum at varying $\Phi$ when $\mathrm{d} v / \mathrm{d} \Phi=0$, i.e. when

$$
[\Phi]=\sqrt{\frac{k_{1} k_{5}[w]}{k_{3} k_{6}}}
$$

An analogous treatment of the alternative explanation of the inhibition yields

$$
v=\frac{k_{1} k_{3} k_{5} k_{8} \mathrm{i}[\Phi][w]}{k_{1} k_{3} k_{7}[\Phi]^{2}+k_{3} k_{8}\left(k_{1}+k_{5} w\right)[\Phi]+k_{1} k_{5} k_{8} w}
$$

and

$$
[\Phi]_{\mathrm{opt}}=\sqrt{\frac{k_{5} k_{8}[w]}{k_{\mathrm{3}} k_{7}}}
$$

The respiration experiments can be treated similarly*, but a different value of $k_{1}$ applies. Since $\left(c_{1}\right)_{\text {opt }}$ differs for ATPase and respiration, $k_{1}$ would be expected to appear in the value of $[\Phi]_{\text {opt }}$. This is the case with the HüLSMANN mechanism, but not with the alternative mechanism for the inhibition which has been considered, although in view of the various assumptions necessary in the kinetic treatment the latter mechanism cannot be excluded by these considerations.

Thus $[\Phi]_{\text {opt }}=k \sqrt{[w]}$, where $w$ represents $\mathrm{H}^{+}$or $\mathrm{OH}^{-}$. If Reaction 3 takes place without the participation of $\mathrm{H}^{+}$or $\mathrm{OH}^{-},[w]$ disappears from this relationship and $[\Phi]_{\text {opt }}$ becomes independent of $\mathrm{pH}$.

* The additional assumption must be made that the velocity of Reaction ra depends only on the concentration of $I$. 
TABLE I

SUMMARY OE THE THEORETICALLY POSSIBLE VALUES OF $\mathrm{dp}\left(c_{1}\right)_{\mathrm{opt}} / \mathrm{dpH}$

\begin{tabular}{|c|c|c|c|c|c|c|c|}
\hline \multirow[b]{2}{*}{ Combination } & \multicolumn{2}{|c|}{ Phenol } & \multicolumn{3}{|c|}{ Water ion } & \multirow[b]{2}{*}{$\left(c_{l}\right)_{\text {opt }}$} & \multirow[b]{2}{*}{$\mathrm{d} p\left(c_{l}\right)_{o p t} / \mathrm{d} p H$} \\
\hline & $\begin{array}{l}\text { undis- } \\
\text { sociated } \\
\text { moleoule }\end{array}$ & ion & $H^{+}$ & $\mathrm{OH}^{-}$ & neither & & \\
\hline a & + & & + & & & $k \sqrt{\left[\mathrm{H}^{+}\right]}$ & +0.5 \\
\hline b & 4 & & & + & & $k \sqrt{\frac{\mathrm{IO}^{-14}}{\left[\mathrm{H}^{+}\right]}}$ & -0.5 \\
\hline c & + & & & & + & $k$ & o \\
\hline d & & + & + & & & $\frac{k}{K} \cdot\left[\mathrm{H}^{+}\right]^{1.5}$ & $+\mathrm{r} .5$ \\
\hline e & & + & & + & & $\frac{k}{K} \sqrt{\left[\mathrm{H}^{+}\right] \mathrm{ro}^{-14}}$ & +0.5 \\
\hline$f$ & & + & & & + & $\frac{k}{K} \cdot\left[\mathrm{H}^{+}\right]$ & + r.o \\
\hline
\end{tabular}

\section{TABLE II}

SUMMARY OF THE DATA ON THE SLOPES (a)-OF THE LINES RELATING P( $c_{1}$ ) opt AND pH

Column I states whether unsubstituted (U) or substituted (S) uncouplers were used. Column 2 gives the slopes $\left(a_{\mathrm{aq}}\right)$ of the lines found for the relation between $\mathrm{p}\left(c_{\mathrm{aq}}\right)_{\mathrm{opt}}$ and $\mathrm{pH}$ when $\mathrm{pH} \gg \mathrm{p} K$. Column 3 shows whether there is a bend when $\mathrm{pH}=\mathrm{p} K$. As there were no substituted compounds with a $\mathrm{p} K$ in the region $5-8$ this is not known for the substituted uncouplers. Columns 4 and 5 show, respectively, whether there is a variation of $\left(c_{\mathrm{aqq}}\right)_{\text {opt }}$ with the partition coefficient or with the amount of mitochondria present. Column 7 gives the values of $a_{1}$, which can be calculated from $a_{\mathrm{aq}}$ (Column 2) by substitution of the empirical relationship $\mathrm{p}\left(c_{\mathrm{aq}}\right)_{\mathrm{opt}}=a \mathrm{pH}+b$ in Eqn. I

$$
\mathrm{p} c_{\mathbf{1}}=\mathrm{p} c_{\mathrm{aq}}+\mathrm{pH}+\mathrm{p} Q+\log \left(K+\left[\mathrm{H}^{+}\right]+f Q\left[\mathrm{H}^{+}\right]\right)
$$

This equation has three limiting cases ${ }^{3}$

I $\mathrm{p} c_{1}=\mathrm{p} c_{\mathrm{aq}}+\mathrm{pH}+\mathrm{p} Q-\mathrm{p} K$

II $\mathrm{p} c_{1}=\mathrm{p} c_{\mathrm{aq}}+\mathrm{p} Q$

III $\mathrm{p} c_{1}=\mathrm{p} c_{\mathrm{aq}}+\log f$

Which of the three has to be used is derived from Columns 4 and 5 . The result is given in Column 6. Column 8 gives the combination (Table I) proposed for the uncoupling system studied.

\begin{tabular}{|c|c|c|c|c|c|c|c|c|}
\hline \multirow{2}{*}{ System used } & \multicolumn{8}{|c|}{ Column } \\
\hline & $I$ & 2 & 3 & 4 & 5 & 6 & 7. & 8 \\
\hline $\begin{array}{l}\text { Succinate } \\
\text { respiration } \\
\text { Pyruvate } \\
\text { respiration } \\
\beta \text {-Hydroxybutyrate } \\
\text { respiration } \\
\text { Glutamate } \\
\text { respiration } \\
\text { ATPase }\end{array}$ & $\begin{array}{l}\mathrm{U} \\
\mathrm{S} \\
\mathrm{U} \\
\mathrm{S} \\
\mathrm{U} \\
\mathrm{S} \\
\mathrm{U} \\
\mathrm{S} \\
\mathrm{U} \\
\mathrm{S}\end{array}$ & $\begin{array}{c}I \\
I \\
-0.5 \\
0 \\
-0.5 \\
-0.5 \\
-0.5 \\
-0.5 \\
-0.5 \\
-0.25\end{array}$ & $\begin{array}{c}+ \\
? \\
+ \\
? \\
+ \\
? \\
+ \\
? \\
+ \\
?\end{array}$ & $\begin{array}{l}+ \\
+ \\
+ \\
+ \\
+ \\
+ \\
+ \\
+ \\
+ \\
+\end{array}$ & $\begin{array}{l}- \\
\overline{-} \\
+ \\
- \\
- \\
- \\
\overline{-}\end{array}$ & $\begin{array}{c}\text { I } \\
\text { I } \\
\text { I } \\
\text { III } \\
\text { I } \\
\text { I } \\
\text { I } \\
\text { I } \\
\text { I } \\
\text { I \& III }\end{array}$ & $\begin{array}{c}0 \\
0 \\
+0.5 \\
0 \\
+0.5 \\
+0.5 \\
+0.5 \\
+0.5 \\
+0.5 \\
0,0.5\end{array}$ & $\begin{array}{l}c \\
c \\
a(e) \\
c \\
a(e) \\
a(e) \\
a(e) \\
a(e) \\
a(e) \\
a(e), c\end{array}$ \\
\hline
\end{tabular}


It is now necessary to relate $[\Phi]$ to $c_{1}$. If the reacting phenol is the undissociated molecule, $[\Phi]=c_{1}$. If, however, it is the phenolate ion,

$$
[\Phi]=\frac{K}{\left[\mathrm{H}^{+}\right]} \cdot c_{1} .
$$

Thus the relationship between $\mathrm{p}\left(c_{1}\right)_{\text {opt }}$ and $\mathrm{pH}$ will depend upon (i) whether $\mathrm{H}^{+}$, $\mathrm{OH}^{-}$or neither is involved in Reaction 3, and (ii) whether the undissociated phenol or the phenolate ion is involved in Reactions 2 and 3.

The 6 possible combinations and the relationship between $\mathrm{p}\left(c_{1}\right)_{\text {opt }}$ and $\mathrm{pH}$ applicable to each combination are shown in Table I. Table II summarizes the experimental data obtained relevant to these considerations.

\section{DISCUSSION}

\section{Phosphorylation step between flavoprotein and cytochrome $c$}

Since inhibition in the cytochrome oxidase region is not observed with the concentrations of uncouplers used, and oxidation of NAD-linked substrates is inhibited by the Amytal present, the value of $a_{1}$ obtained with succinate as substrate is a property of the phosphorylation step between flavoprotein and cytochrome $c$. Since $a_{1}=0$, it appears, on the basis of our assumptions, that the undissociated phenol molecule reacts with $A \sim \mathrm{I}$, and the $\Phi-\mathrm{I}$ compound dissociates without mediation of $\mathrm{H}^{+}$or $\mathrm{OH}^{-}$.

The optimum $\mathrm{pH}$ of maximally uncoupled succinate oxidation by rat-liver mitochondria (Fig. 4), of the Amytal-resistant dinitrophenol-induced ATPase of rat-liver mitochondria ${ }^{5}$, of the $\mathrm{P}: \mathrm{O}$ ratio with rat-heart sarcosomes oxidizing succinate ${ }^{9}$, and of the succinate oxidase of KEILIN AND HARTREE heart-muscle preparation is in every case close to $\mathrm{pH} 7.4$.

\section{Phosphorylation step between NADH and flavoprotein}

In a previous paper ${ }^{5}$, it was concluded that the dinitrophenol-induced ATPase was made up of contributions from the first two phosphorylation steps of the res-

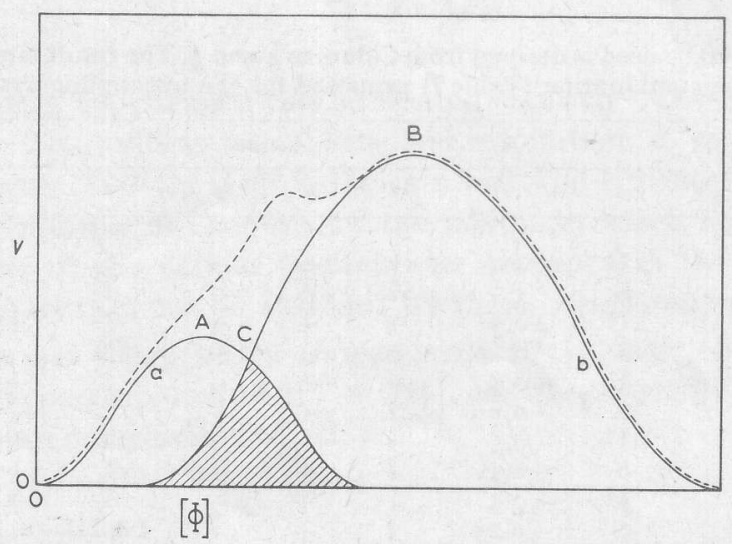

Fig. 6. The combined effect of uncoupling in two phosphorylating steps. For explanation see text. 
piratory chain, the first (i.e. the one between $\mathrm{NADH}$ and flavoprotein) contributing about two-thirds. Higher concentrations of dinitrophenols were required to induce this ATPase. Schematically, these findings can be represented as in Fig. 6, where curves $\mathrm{b}$ and a represent the contribution of the first and second phosphorylation step, respectively, and the dotted line the total activity. Two peaks are shown on this curve, but the dominant peak is that due to the first phosphorylation step.

The situation is quite different in respiration experiments, since the least active step of the respiratory chain limits the overall rate of respiration. If Fig. 6 now represents the respiratory activity of the two steps, the borders of the area in which both curves overlap (the striated årea) represent the respiration- $[\Phi]$ curve. Maximum activity will be found at $C$, which is not far from $A$, the peak of the less active step. Unfortunately, it is not easy to be sure which this is. Since, however, the behaviour of succinate respiration with respect to the variables summarized in Table II differs from that "of the respiration with other substrates, it seems likely that the effects of variation of lipid solubility of the uncoupling phenol and of $\mathrm{pH}$ of the reaction medium on the rate of oxidation of NAD-linked substrates reflect the behaviour of the first phosphorylation step.

The difference between pyruvate ( + malate) and the other NAD-linked substrates has already been noted. It was concluded that $f Q\left[\mathrm{H}^{+}\right] \gg\left[\mathrm{H}^{+}\right]$and $K$ in the case of pyruvate ( + malate) and is $\ll\left[\mathrm{H}^{+}\right]$and $K$ in the case of the other substrates. Since the experiments were carried out in the same $\mathrm{pH}$ range and with the same concentration of mitochondria (i.e.f), it must be concluded that $Q$ differs in the two cases, being much greater when pyruvate $(+$ malate $)$ is substrate. This leads to the conclusion that the enzymes involved in oxidative phosphorylation with pyruvate (+ malate) as substrate are located in a much more lipophilic region of the mitochondrion than is the case when glutamate or $\beta$-hydroxybutyrate is substrate.

This is an unexpected conclusion, but would provide a physical basis for the postulate of CHANCE ${ }^{14,15}$ and KLINGENBERG ${ }^{16}$ of compartmentation of mitochondrial NAD, based on the different degrees of reduction obtained with different substrates:

In all cases of NAD-linked substrates, except pyruvate $(+$ malate) in the presence of the lipophilic alkyldinitrophenols, the value of $a_{1}$ calculated from the observed values of $a_{\mathrm{aq}}$ was found to be 0.5 (see Table II). This can be explained by either combination a (undissociated phenol and $\mathrm{H}^{+}$) or combination e (phenolate ion and $\left.\mathrm{OH}^{-}\right)$,

i.e.

or

$$
\begin{gathered}
\mathrm{NAD} \sim \mathrm{I}+\Phi-\mathrm{OH} \rightarrow \mathrm{NAD}^{+}+\Phi-\mathrm{I} \\
\Phi-\mathrm{I}+\mathrm{H}^{+} \rightleftharpoons \Phi-\mathrm{OH}+\mathrm{I}
\end{gathered}
$$

$$
\begin{gathered}
\mathrm{NAD} \sim \mathrm{I}+\Phi-\mathrm{O}^{-} \rightarrow \mathrm{NAD}^{+}+\Phi-\mathrm{I} \\
\Phi-\mathrm{I}+\mathrm{OH}^{-} \rightleftharpoons \Phi-\mathrm{OH}+\mathrm{I}
\end{gathered}
$$

With pyruvate $(+$ malate $)$ and alkyldinitrophenols, $a_{1}=0$, so that the mechanism is presumably

$$
\begin{gathered}
\mathrm{NAD} \sim \mathrm{I}+\Phi-\mathrm{OH} \rightleftharpoons \mathrm{NAD}^{+}+\Phi-\mathrm{I} \\
\Phi-\mathrm{I} \rightleftharpoons \Phi+\mathrm{I}
\end{gathered}
$$

similar in principle to that operating in the second phosphorylation step (see above). 
The conclusion that neither $\mathrm{H}^{+}$nor $\mathrm{OH}^{-}$plays a role in the dissociation of $\Phi-\mathrm{I}$ is in agreement with the conclusion that this reaction takes place in a more lipophilic region of the mitochondrion.

Although nö final decision can be made between combinations a and e, there is one consideration which favours the former. Since the undissociated phenol appears to be involved in Reaction 2 in the second phosphorylation step, and with the first phosphorylation step with pyruvate ( + malate) and alkyldinitrophenols, there is some reason to expect that this would also be so in the other cases.

The value for $a_{\mathrm{aq}}$ for the ATPase induced by unsubstituted nitrophenols is -0.5 , giving +0.5 for $a_{1}$ (Table II). Since, as explained above, this corresponds to the first phosphorylation step, this value is in agreement with the conclusions drawn from the behaviour of respiration uncoupled with unsubstituted nitrophenols. With alkyldinitrophenols, however, values of $a_{\mathrm{aq}}$ between -0.2 and -0.3 were obtained, indicating rather strongly that two parallel systems are operating, one with $a_{\mathrm{aq}}$ of o and the other of -0.5 . These two systems are probably the twa mechanisms linked with the NADH-flavoprotein region located in the different mitochondrial compartments as discussed above.

The $\mathrm{pH}$ optimum of the maximally uncoupled pyruvate $(+$ malate) oxidation was found to be 6.8 (Fig. 5), identical with the $\mathrm{pH}$ optimum of the dinitrophenolinduced ATPase ${ }^{5}$.

\section{ACKNOWLEDGEMENTS}

The author is very grateful to Professor E. C. Slater and Dr. W. C. Hülsmann for many helpful discussions and criticism and to Professor E. C. SLATER and Dr. J. P. Colpa-Boonstra for reading and discussing the manuscript. The expert technical assistance of Miss W. NuWENHOF is also gratefully acknowledged.

This work was supported in part by the U.S. Public Health Service grant RG 6569..

\section{REFERENCES}

1 H. C. HEMKer, Het mechanisme van de werking van ontkoppelende fenolen op de ademhalingsketenfosforylering. M.D. Thesis, Klein Offset Drukkerij, Amsterdam, I962.

2 H. C. Hemker, Biochim. Biophys. Acta, 8I (I964) I.

3 H. C. Hemker and W. C. Hülsmann, Biochim. Biophys. Acta, 48 (I96I) 22 I.

4 H. C. Hemker, Biochim. Biophys. Acta, 63 (I962) 46.

5 H. C. Hemker, Biochim. Biophys. Acta, 73 ( 1963 ) 3i 1 ,

6 H. C. Hemker, Biochim. Biophys. Acta, 60 (1962) 646.

7 E. C. Slater, Proc. Intern. Symp. Enzyme Chem., Tokyo and Kyoto, I957, Maruzen, Tokyo, I 958 , P. 288.

8 P. Greengard, K. Minnaert, E. C. Slater and I. Betel, Biochem. J., 73 (1959) 637.

3 W. C. HÜLSMANN, Over het mechanisme van de ademhalingsketenfosforylering, M.D. Thesis, Klein Offset Drukkerij, Amsterdam, I958.

10 P. Mitchell, Nature, I9I (I96I) I44.

11 E. C. Slater, Rev. Pure Appl. Chem., 8 (I958) 22 I.

12 C. L. WAdkins and A. L. Lehninger, J. Biol. Chem., 234 (I959) 68I.

13 W. Chefurka, Can. J. Biochem. Physiol., 38 (1960) II95.

14 B. Chance and G. Hollunger, Federation Proc., 20 (I96I) I.

15 B. Chance and G. Hollunger, J. Biol. Chem., 236 (I96I) I 534, I555, I 562, I 577.

16 M. Klingenberg and P. Scholmeyer, Biochem. Z., 333 (I960) 335. 